\title{
A novel P20R mutation in the alpha-B crystallin gene causes autosomal dominant congenital posterior polar cataracts in a Chinese family
}

Xin-Yi Xia ${ }^{1 \dagger}$, Qiu-Yue Wu ${ }^{1 \dagger}$, Li-Mei An ${ }^{1}$, Wei-Wei Li ${ }^{1}$, Na Li ${ }^{1}$, Tian-Fu Li ${ }^{1}$, Cui Zhang ${ }^{1}$, Ying-Xia Cui ${ }^{1}$, Xiao-Jun Li ${ }^{1 *}$ and Chun-Yan $X u e^{1,2^{*}}$

\begin{abstract}
Background: To identify the genetic defects and investigate the possible mechanism of cataract genesis in a five-generation family with autosomal dominant congenital posterior polar cataracts.

Methods: Clinical data were collected, and the lens phenotypes of the affected members in this family were recorded by slit lamp photography. Genomic DNA was isolated from peripheral blood using QIAamp DNA Blood Mini Kits. Twenty-three mutational hot spots associated with autosomal dominant congenital posterior polar cataracts were screened by PCR-based DNA sequencing. Properties and structural models of wild-type and mutant alpha-B (aB)-crystallin (CRYAB) were generated and analyzed using SWISS-MODEL.

Results: All affected individuals in this family started to exhibit poor vision at the age of 8-10 years. The lens opacity consisted of a single, well-defined plaque, $0.5-3 \mathrm{~mm}$ in diameter, which was confined to the posterior pole of the lens. DNA sequencing analysis of the affected members showed a novel, heterozygous missense mutation c.59C > G (P2OR) in exon 1 of the CRYAB gene. This mutation was not found in 10 unaffected family members, or in 200 unaffected and unrelated individuals, thereby excluding the possibility that it is a rare polymorphism. Data generated using the ProtScale and PyMOL programs revealed that the mutation altered the stability and solubility of the aB-crystallin protein.
\end{abstract}

Conclusions: This study reported a novel c.59C > G (P20R) missense mutation in CRYAB in a five-generation Chinese family with posterior polar cataract.

Keywords: Congenital posterior polar cataract, Alpha-B crystallin gene, P20R mutation

\section{Background}

Hereditary congenital cataract [OMIM 604307] is an opacification of the lens of the eye, which causes visual impairment or even blindness during infancy or early childhood. Cataracts can be clinically classified into many different types, such as posterior polar, anterior polar, and lamellar. Around one-third of congenital cataracts can be inherited in an autosomal dominant, autosomal recessive, or X-linked manner, although autosomal dominant

\footnotetext{
*Correspondence: lixiaojun1962@gmail.com; xuechunyan1973@gmail.com ${ }^{\dagger}$ Equal contributors

'Institute of Laboratory Medicine, Jinling Hospital, Nanjing University School of Medicine, 305 East Zhongshan Road, Nanjing 210002, People's Republic of China

${ }^{2}$ Department of Ophthalmology, Jinling Hospital, Nanjing University School of Medicine, Nanjing, People's Republic of China
}

inheritance of congenital cataracts predominates. Thus far, congenital cataracts have been associated with the following genes: 10 crystallin genes (CRYAA, CRYAB, CRYBB1, CRYBB2, CRYBA1/A3, CRYGA, CRYGB, CRYGC, CRYGD, CRYGS) [1-4], 3 membrane protein genes (GJA3, GJA8 and MIP) [5-7], beaded filament structural protein-2 (BFSP2) [8], a ferritin light chain gene $(T F L)$ [9], transcription regulatory factors genes (MAF, PITX3, HSF4, PAX6) [10-12], connexin 46 (Cx46) [13], aspartate-47 of the Connexin50 gene (Cx50D47) [14], a receptor tyrosine kinase gene (EPHA2) [15], and the Wolfram gene (WFS1) [16].

The water-soluble crystallins are the most abundant proteins in the lens and have a critical role in maintaining lens transparency. They are mainly composed of two related 
proteins, $\alpha \mathrm{A}$ - and $\alpha \mathrm{B}$-crystallins, encoded by the CRYAA and $C R Y A B$ genes, which are present in a 3:1 ratio. Both proteins belong to the small heat shock protein (sHSP) family and function as molecular chaperones to prevent the stress-induced aggregation of other proteins [17]. $\alpha \mathrm{A}-$ and $\alpha \mathrm{B}$-crystallins form hetero-oligomers that bind and sequester damaged proteins, preventing the formation of particulates that scatter light [18]. CRYAA is mainly expressed at a high level in the lens, while CRYAB is widely expressed in a variety of tissues and is associated with neurologic, cardiac, and muscular disorders [18]. The CRYAB gene comprises three exons and encodes a small, 175 amino acid protein belonging to the sHSP family [19], which acts as a molecular chaperone, preventing the aggregation of denatured proteins after the exposure to stresses, such as heat shock, radiation, oxidative stress and anticancer drugs [20]. Besides being found in the lens, $\alpha \mathrm{B}$-crystallin is distributed in other tissues and organs, including the brain, heart, stomach, lung, kidney, muscle, and retina. Mutations in the CRYAB gene cause distinct clinical phenotypes, including isolated cataract, myofibrillar myopathy, cardiomyopathy, or a multi-systemic disorder combining these features [18].

In the present study, we first investigated a fivegeneration Chinese family with autosomal dominant, isolated, congenital, posterior polar cataract and identified a novel missense mutation in exon 1 of $C R Y A B$ that leads to an exchange of proline for arginine at codon 20 (P20R).

\section{Methods}

\section{Participant and clinical data}

A five-generation Chinese cataract family was enrolled at Nanjing General Hospital of the Nanjing Military Region Ophthalmic Center. Sixteen living family members (Figure 1), including 6 affected and 10 unaffected subjects, underwent full ophthalmic examinations, including visual acuity, slit-lamp microscopy, fundus examination, intraocular pressure, and B-ultrasonic scanning. Additionally, they underwent a systematic medical assessment, which included serum creatine kinase level, electrocardiography (ECG), echocardiography, muscular tension, and muscular reflexes of the proximal and distal muscles of the lower and upper limbs. Two hundred unrelated and unaffected individuals were collected to be normal controls in the study.

All procedures used in the study confirmed to the tenets of the Declaration of Helsinki. The Ethics Committee of Jinling Hospital approved all study protocols. All participants had knowledge of their participation in the study. Written informed consent was obtained from all participants.

\section{Mutation screening}

Genomic DNA was extracted from the peripheral blood of the patients using QIAamp DNA Blood Kits (Qiagen,
German). Mutation screening was performed using a candidate gene approach. Known candidate genes for hereditary cataracts, such as CRYAA, CRYAB, CRYBA1/ 3, CRYBB1, CRYBB2, CRYGA-D, CRYGS, GJA3, GJA8, MIP, HSF4, BFSP2, FTL, MAF, PITX3, PAX6, CX46, Cx50D47, EPHA2 and WFS1 were analyzed by polymerase chain reaction (PCR) amplification, followed by direct DNA sequencing. The specific primer pairs are given in Additional file 1. The sequencing results were analyzed using Chromas (version 2.3) and compared with reference sequences in the National Center for Biotechnology Information (NCBI) database.

\section{Bioinformatics analysis of protein structures and properties}

Biophysical predictions of the altered $\alpha \mathrm{B}$-crystallin protein were analyzed using bioinformatics tools. In particular, we used ProtScale (provided by the Swiss Institute of Bioinformatics, Geneva, Switzerland) to examine hydrophilicity. The resulting protein database files were visualized using Swiss-PDB Viewer (version 4.01, provided by the Swiss Institute of Bioinformatics, Geneva, Switzerland).

\section{Alignment analysis}

ClustalW (version 1.83) was used to compare the sequence of CRYAB (Homo sapiens, NP_001276736.1) with orthologs of Rattus norvegicus (NP_037067.1), Danio rerio (NP_571232.1), Ovis aries (NP_001012475.1), Sus scrofa (XP_005667376.1), and Pongo abelii (NP_001125917.1).

\section{Results}

\section{Clinical findings}

The cataracts in this family were inherited in an autosomal dominant manner and appeared to be of the congenital, posterior polar type. All affected individuals started to have poor vision at the age of 8-10 years. Lens opacity, which was bilateral in all cases, consisted of a single, well-defined plaque, $0.5-3 \mathrm{~mm}$ in diameter, which was confined to the posterior pole of the lens (Figure 2). Clinical investigation including visual acuity, age of onset in each affected subjects were described in Table 1 . No other systemic findings in the cardiovascular and muscular systems were identified in any of the affected members.

\section{Sequence analysis}

Multiple genes that could potentially cause congenital cataracts were screened by PCR-based DNA sequencing. No mutation was found in any gene, except for $C R Y A B$. Sequencing analysis revealed that the $C R Y A B$ gene segment carried a novel $\mathrm{C}>\mathrm{G}$ heterozygous mutation at nucleotide 59 in exon 1 of the gene in all six affected family members. This mutation was not found in the 10 


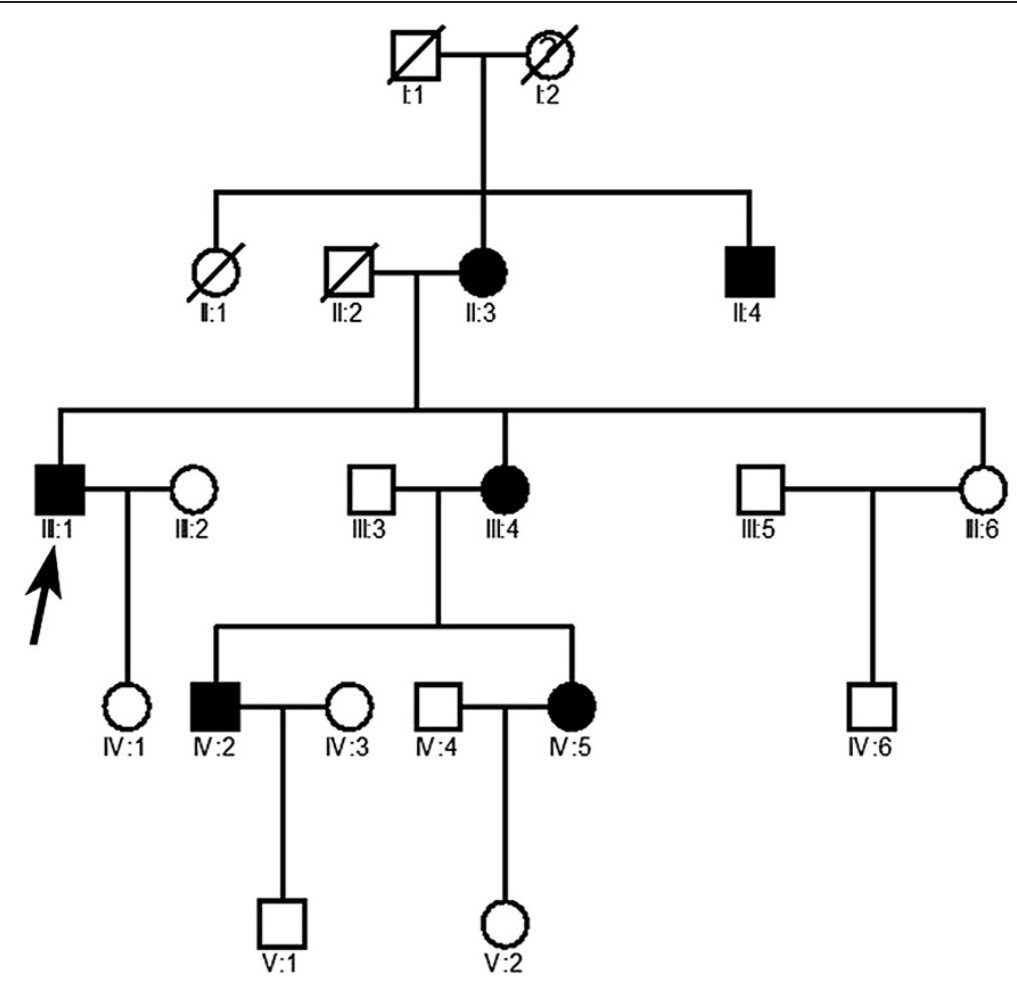

Figure 1 The Chinese pedigree with congenital posterior polar cataract. The transmission pattern suggests the cataract is inherited in an autosomal dominant manner. Square symbols: males; round symbols: females; shaded symbols: ophthalmologist-confirmed posterior polar cataract; question mark (12 member in the family): a poor vision which was suspected to have a cataract, but could not be diagnosed clearly. arrow: proband.

unaffected members or in the 200 unaffected and unrelated normal controls (Figure 3). The c.59C > G (P20R) mutation in CRYAB was not listed in the NCBI SNP database (dbSNP), Exome Variant Server or Human Gene Mutation Database (HGMD), which excludes the possibility that it is a rare polymorphism. At the protein level, it led to an amino acid change from proline to arginine at amino acid 20 (P20R). This indicated that the missense mutation (c.59C $>\mathrm{G}$ ) was the cause of posterior polar cataract in this pedigree. In addition, the Pro20 residue is highly conserved across species, as shown in Figure 4.

\section{Bioinformatics analysis}

To better understand the effects of the mutation on the biochemical properties and structure of the $\alpha \mathrm{B}$-crystallin protein, the hydrophilicity of the corresponding region was predicted using the program ProtScale, which indicated that the mutant $\alpha \mathrm{B}$-crystallin showed lower hydrophilicity in the mutated region compared with the wildtype protein (Figure 5). Consistent with the change of hydrophilicity, the isoelectric point (pI) of the $\alpha \mathrm{B}$ crystallin protein also changed, from $\mathrm{pH} 6.90$ in the wild-type protein to $\mathrm{pH} 8.56$ in the mutant protein.

\section{Discussion}

Posterior polar cataract is a significant opacity that is distributed at the back of the lens. Because of its proximity to the optical center of the eye, it can have a great effect on visual acuity [21]. Here, we reported a novel c.59C > G (P20R) missense mutation in the CRYAB gene in a five-generation Chinese family with posterior polar cataract. The alpha- $B$ crystallin protein encoded by $C R Y A B$ is composed of three domains: an $\mathrm{NH} 2-$ terminal tail, the $\alpha \mathrm{B}$ crystallin domain (ACD), and a $\mathrm{COOH}$-terminal extension. The $\mathrm{NH} 2$-terminal domain is encoded by the first exon, which controls the chaperone function of the protein [22]. The P20R mutation is located in the NH2-terminal domain, and the Pro20 residue is highly conserved across species, which suggests that it plays a key role in the structure and function of the protein.

Since the first description of a CRYAB mutation (R120G) leading to associated disease in 1998 [14], only a few additional mutations have been reported. These mutations cause markedly different clinical features, such as isolated cataract, myofibrillar myopathy, cardiomyopathy, or a multi-systemic disorder combining these phenotypes [13]. 


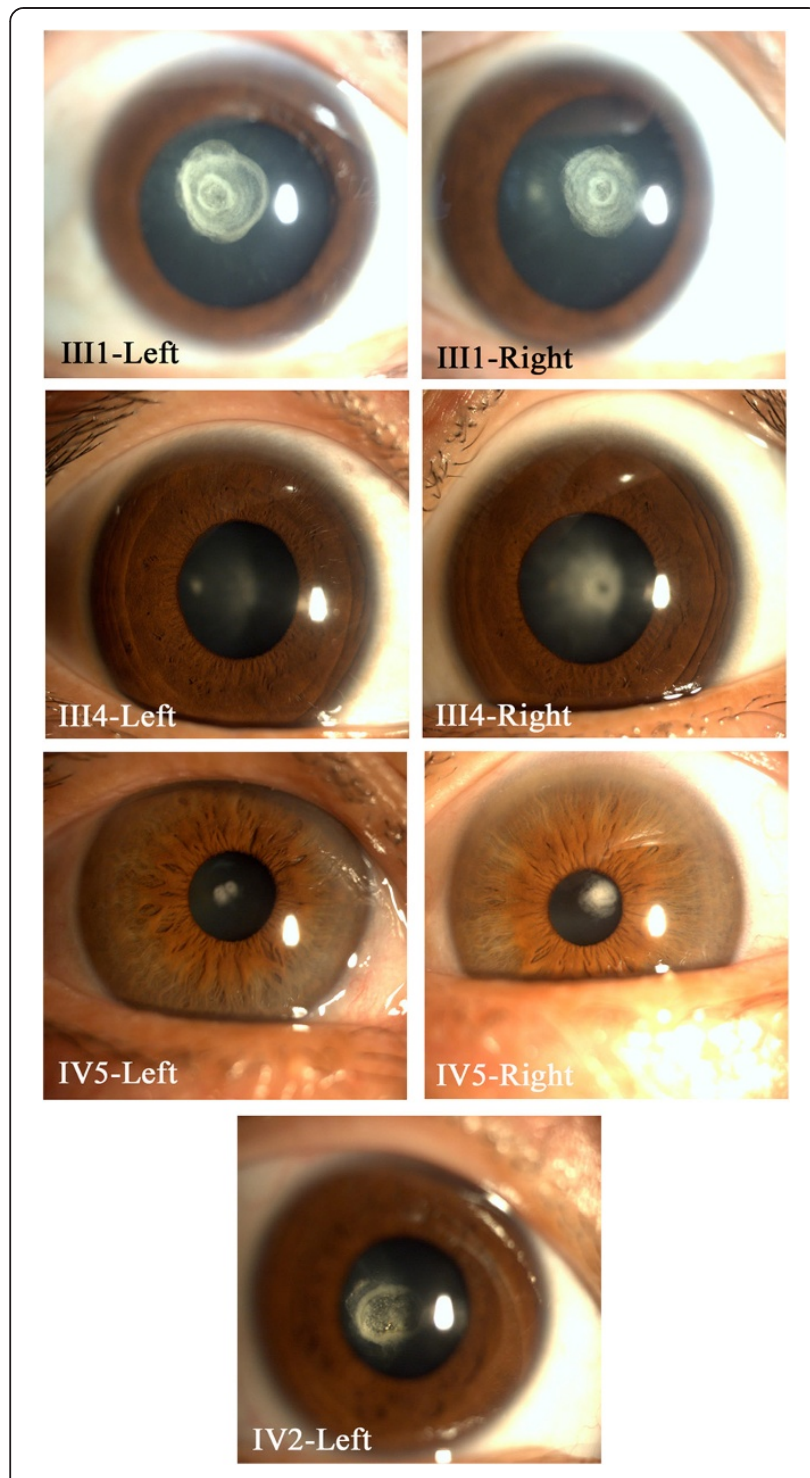

Figure 2 The part of slit-lamp photograph of the dilated eye of the affected family member (III1, III4, IV2 and IV5). The opacity consisted of a single well-defined plaque, $0.5-3 \mathrm{~mm}$ in diameter, which was confined to the posterior pole of the lens. The slit lamp pictures of $\| 13$ and $\| 4$ could not be got because of surgery in the other hospital. The picture of Oculus Dexter in IV2 had a bad quality that could not be offered.

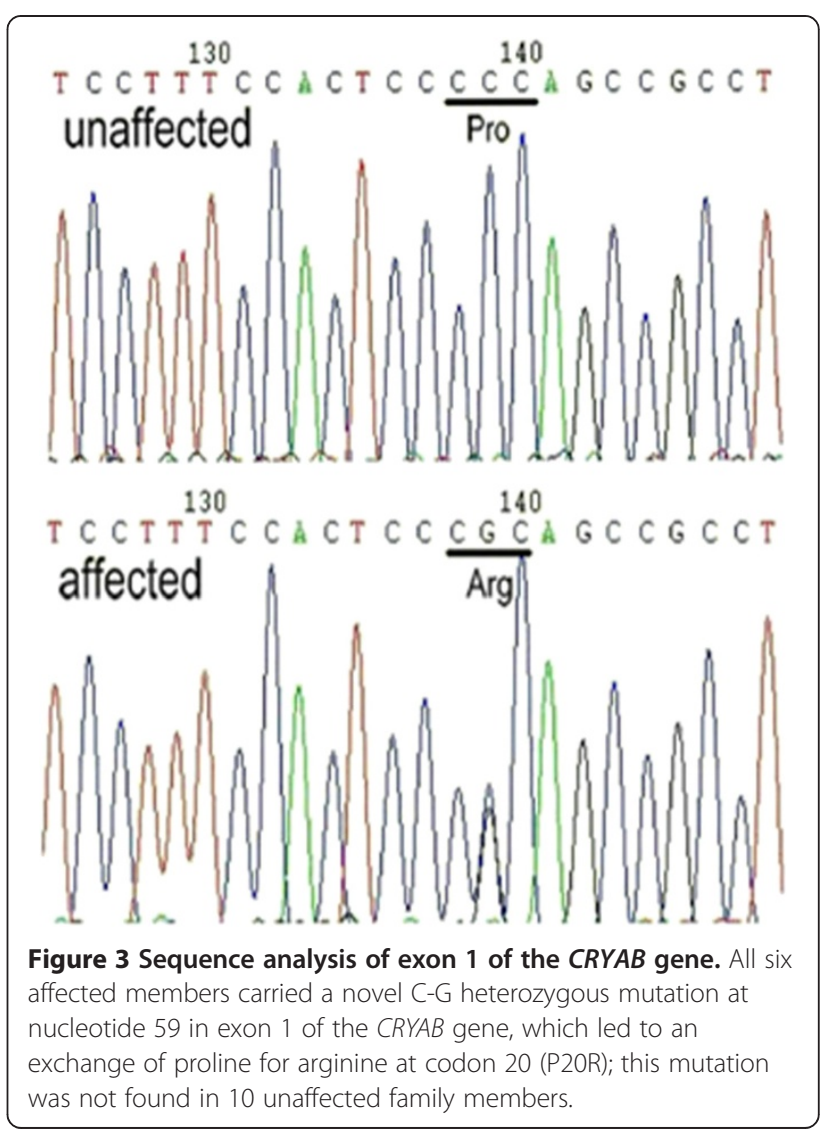

Thus far, eight mutations in the CRYAB gene associated with isolated cataract have been described, including this study. All eight CRYAB mutations and the corresponding clinical features are summarized in Table 2 [3,18,20,21,23-25]. Most reported CRYAB mutations (7/8) were dominant, although Safieh et al. reported that an autosomal recessive mutation, R56W, resulted in cataract [23]. Four out of the eight isolated cataract-causing mutations are located in exon 1 . It is noted that two mutations occur at an evolutionarily conserved residue, Pro20, indicating a potential hotspot involved in cataract. It seems that mutations outside the $\alpha$-crystallin domain result in isolated cataract. In 2006, Liu et al. stated that a family with isolated

Table 1 Clinical data in each affected subjects

\begin{tabular}{ccccccc}
\hline Number & Onset Age & Op. Age & \multicolumn{2}{c}{ Preop. BCVA } & & \multicolumn{2}{c}{ Postop. BCVA } \\
\cline { 5 - 6 } & & & OD & OD & & OS \\
\hline II3 & No available & 16 & No available & No available & $20 / 50$ & $20 / 40$ \\
II4 & No available & 17 & No available & No available & $20 / 40$ & $20 / 30$ \\
III & 12 & 20 & $20 / 200$ & $20 / 100$ & $20 / 40$ & $20 / 30$ \\
III & 10 & 19 & $20 / 100$ & $20 / 125$ & $20 / 30$ & $20 / 50$ \\
IV2 & 9 & 11 & $20 / 100$ & $20 / 80$ & No available & No available \\
IV5 & 8 & No available & $20 / 40$ & $20 / 50$ & &
\end{tabular}

Op.: operation; BCVA: best corrected visual acuity; OD: Oculus Dexter; OS: Oculus Sinister 


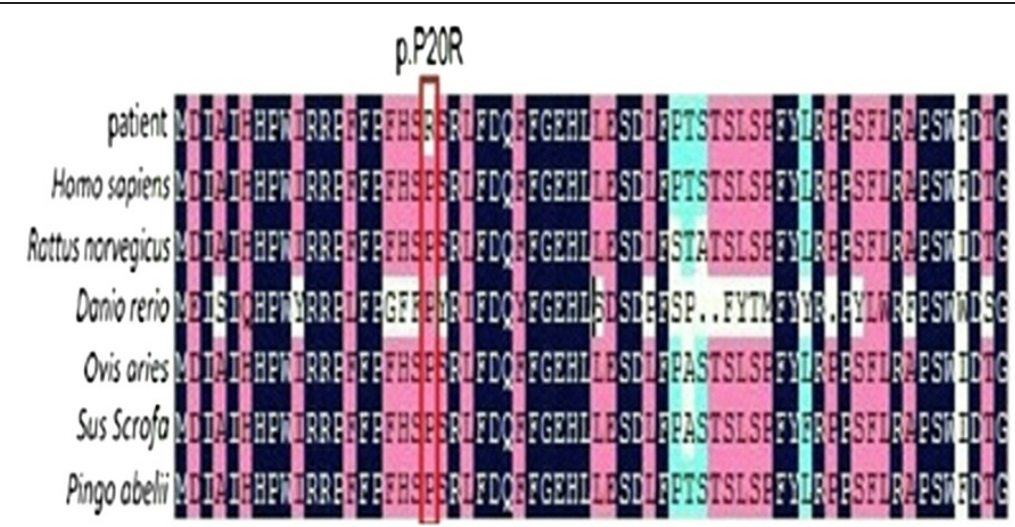

Figure 4 Protein sequence alignments. The P2OR substitution of the alpha-B crystallin polypeptide occurs in a highly conserved amino acid residue, as shown in this cross-species alignment.

posterior polar cataract carried a P20S mutation [3]. As $\alpha \mathrm{B}$-crystallin interacts with $\alpha \mathrm{A}$-crystallin, a mutant $\alpha B$-crystallin with the P20S mutation may act in a dominant negative manner, thereby interfering with the function of $\alpha \mathrm{A}$-crystallin and leading to the formation of cataracts early in the lives of individuals who carry the mutation. Additionally, the mutant $\alpha B$ crystallin no longer possessed the ability to inhibit apoptosis of lens epithelial cells, which resulted in the development of cataracts. The paper reported by $\mathrm{Li}$ et al. also confirmed that the cataract causing P20S mutation of $\alpha \mathrm{B}$-crystallin impaired the chaperone activity of $\alpha \mathrm{A}$-crystallin and induced apoptosis of human lens epithelial cells [22]. In a recent study, it was suggested that the P20S mutation altered the secondary structure of the $\alpha B$-crystallin protein, as shown by increasing $\alpha$-helical and decreasing $\beta$-sheet contents, and changed the tertiary structure, which may influence protein stability and conformation and induce the formation of aggregates [26]. Our results indicated that P20R mutation changes the hydrophilicity and isoelectric point, but not the secondary and tertiary structure, of $\alpha \mathrm{B}$-crystallin, potentially lowering the solubility of the mutant protein. Therefore, we speculate that the P20R mutation lowers the solubility of the mutant $\alpha B$ crystallin, causing protein self-aggregation and resulting in a more stable heteroaggregate with $\alpha \mathrm{A}$-crystallin. Additionally, it may affect the chaperone function of $\alpha$-crystallin, thereby further contributing to the development of cataracts.

\section{Conclusions}

Here, we reported a novel c.59C > G (P20R) missense mutation in $C R Y A B$ in a five-generation Chinese family with
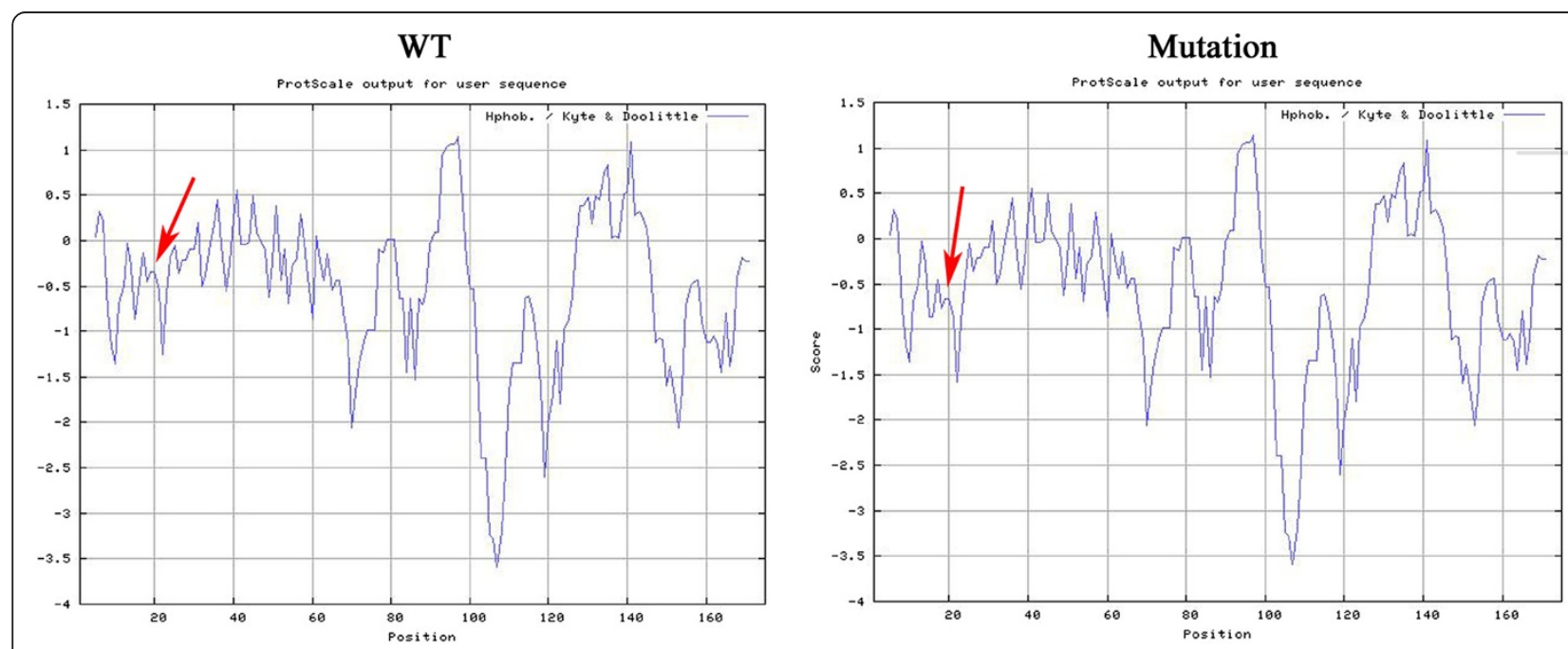

Figure 5 Hydropathy plot of wild-type and mutated aB-crystallin. Obviously, the mutant aB-crystallin showed lower hydrophilicity in the mutated region compared with the wild-type protein (indicated by red arrows). 
Table 2 CRYAB gene mutations associated with isolated congenital cataracts

\begin{tabular}{|c|c|c|c|c|c|c|}
\hline No. & Inheritance mode & Exon & Nucleotide change & Amino acid change & Clinical features & Reference \\
\hline 1 & $A D$ & 1 & c. $32 \mathrm{G}>\mathrm{A}$ & p.R11H & Nuclear cataract & [18] \\
\hline 2 & $A D$ & 1 & c.58 C > T & p.P2OS & Posterior polar cataract & {$[3]$} \\
\hline 3 & $A D$ & 1 & C. 59 C > G & p.P20R & Posterior polar cataract & Present study \\
\hline 4 & $A R$ & 1 & c. 166 C > T & p.R56W & Dense complete white cataracts & [23] \\
\hline 5 & $A D$ & 2 & c. 205 C > T & p.R69C & N/A & [24] \\
\hline 6 & $A D$ & 3 & C. $418 \mathrm{G}>\mathrm{A}$ & p.D140N & Lamellar cataract & {$[25]$} \\
\hline 7 & $A D$ & 3 & c.450 del A & Frameshift & Posterior polar cataract & [20] \\
\hline 8 & $A D$ & 3 & c.557 G > A & p.A171T & Lamellar cataract & [21] \\
\hline
\end{tabular}

$A D$, Autosomal dominant; $A R$, Autosomal recessive; N/A, not available.

posterior polar cataract. Additionally, the P20R mutation changed the hydrophilicity and isoelectric point of $\alpha B$ crystallin to lower the solubility of the mutant protein.

\section{Additional file}

Additional file 1: Table Primers for mutational analysis of congenital cataract.

\section{Abbreviations \\ CRYAA: Crystallin, alpha A; CRYAB: Crystallin, alpha B; CRYBB1: Crystallin, beta B1; CRYBB2: Crystallin, beta B2; CRYBA1: Crystallin, beta A1; CRYBA2: Crystallin, beta A2; CRYBA3: Crystallin, betaA3; CRYGA: Crystallin, gamma A; \\ CRYGB: Crystallin, gamma B; CRYGC: Crystallin, gamma C; CRYGD: Crystallin, gamma D; CRYGS: Crystallin, gamma S; GJA3: Gap junction protein, alpha 3; GJA8: Gap junction protein, alpha 8; MIP: Major intrinsic protein of lens fiber; BFSP2: Beaded filament structural protein-2; FTL: Ferritin light chain gene; MAF: v-maf avian musculoaponeurotic fibrosarcoma oncogene homolog; PITX3: Paired-like homeodomain 3; HSF4: Heat shock transcription factor 4; PAX6: Paired box 6; Cx46: Connexin 46; Cx50D47: Geneaspartate-47 of Connexin50 gene; EPHA2: Receptor tyrosine kinase gene; WFS1: Wolfram gene; sHSP: Small heat shock proteins family; PCR: Polymerase Chain Reaction; pl: Isoelectric point; ACD: The aB crystallin domain; HGMD: Human Gene Mutation Database.}

\section{Competing interests}

The authors declare that they have no competing interests.

\section{Authors' contributions}

XX and QW carried out the molecular genetic studies and drafted the manuscript. LA participated in the laboratory work. WL, NL, TL and CZ participated in the sequence alignment. YC and XL participated in the design of the study and performed the statistical analysis. CX and XL conceived of the study, and participated in its design and coordination and helped to draft the manuscript. All authors read and approved the final manuscript.

\section{Acknowledgment}

This work was supported by the Natural Science Foundation of Jiangsu province (BK2011660), Key Foundation of Jiangsu Science and Technology Bureau (BM2013058). We thank all members of the family for their cooperation in the study.

Received: 10 March 2014 Accepted: 4 September 2014

Published: 8 September 2014

\section{References}

1. Lu S, Zhao C, Jiao H, Kere J, Tang X, Zhao F, Zhang X, Zhao K, Larsson C: Two Chinese families with pulverulent congenital cataracts and deltaG91 CRYBA1 mutations. Mol Vis 2007, 13(10):1154-1160.
2. Wang J, Ma X, Gu F, Liu NP, Hao XL, Wang KJ, Wang NL, Zhu SQ: A missense mutation S228P in the CRYBB1 gene causes autosomal dominant congenital cataract. Chin Med J (Engl) 2007, 120(9):820-824.

3. Liu M, Ke T, Wang Z, Yang Q, Chang W, Jiang F, Tang Z, Li H, Ren X, Wang X, Wang T, Li Q, Yang J, Liu J, Wang QK: Identification of a CRYAB mutation associated with autosomal dominant posterior polar cataract in a Chinese family. Invest Ophthalmol Vis Sci 2006, 47(8):3461-3466.

4. Gu F, Li R, Ma XX, Shi LS, Huang SZ, Ma X: A missense mutation in the gammaD-crystallin gene CRYGD associated with autosomal dominant congenital cataract in a Chinese family. Mol Vis 2006, 12(1):26-31.

5. Guleria K, Sperling K, Singh D, Varon R, Singh JR, Vanita V: A novel mutation in the connexin 46 (GJA3) gene associated with autosomal dominant congenital cataract in an Indian family. Mol Vis 2007, 13(6):1657-1665.

6. Vanita $V$, Hennies HC, Singh D, Nurnberg P, Sperling K, Singh JR: A novel mutation in GJA8 associated with autosomal dominant congenital cataract in a family of Indian origin. Mol Vis 2006, 12(4):1217-1222.

7. Gu F, Zhai H, Li D, Zhao L, Li C, Huang S, Ma X: A novel mutation in major intrinsic protein of the lens gene (MIP) underlies autosomal dominant cataract in a Chinese family. Mol Vis 2007, 13:1651-1656.

8. Zhang L, Gao L, Li Z, Qin W, Gao W, Cui X, Feng G, Fu S, He L, Liu P: Progressive sutural cataract associated with a BFSP2 mutation in a Chinese family. Mol Vis 2006, 12:1626-1631.

9. Vanita V, Hejtmancik JF, Hennies HC, Guleria K, Nürnberg P, Singh D, Sperling K, Singh JR: Sutural cataract associated with a mutation in the ferritin light chain gene (FTL) in a family of Indian origin. Mol Vis 2006, 12(1):93-99.

10. Bu L, Jin $Y$, Shi $Y$, Chu R, Ban A, Eiberg $H$, Andres $L$, Jiang $H$, Zheng $G$, Qian M, Cui B, Xia Y, Liu J, Hu L, Zhao G, Hayden MR, Kong X: Mutant DNA-binding domain of HSF4 is associated with autosomal dominant lamellar and Marner cataract. Nat Genet 2002, 31(3):276-278.

11. Ke T, Wang QK, Ji B, Wang X, Liu P, Zhang X, Tang Z, Ren X, Liu M: Novel HSF4 Mutation Causes Congenital Total White Cataract in a Chinese Family. Am J Ophthalmol 2006, 142(2):298-303.

12. Burdon KP, McKay JD, Wirth MG, Russell-Eggit IM, Bhatti S, Ruddle JB, Dimasi D, Mackey DA, Craig JE: The PITX3 gene in posterior polar congenital cataract in Australia. Mol Vis 2006, 12(6):367-371.

13. Wang KJ, Zhu SQ: A novel p. F206I mutation in Cx46 associated with autosomal dominant congenital cataract. Mol Vis 2012, 18:968-973.

14. Berthoud VM, Minogue PJ, Yu H, Schroeder R, Snabb Jl, Beyer EC: Connexin50D47A decreases levels of fiber cell connexins and impairs lens fiber cell differentiation. Invest Ophthalmol Visual Sci 2013, 54(12):7614-7622.

15. Dave A, Laurie K, Staffieri SE, Taranath D, Mackey DA, Mitchell P, Wang JJ, Craig JE, Burdon KP, Sharma S: Mutations in the EPHA2 Gene Are a Major Contributor to Inherited Cataracts in South-Eastern Australia. PLoS One 2013, 8(8):e72518.

16. Berry V, Gregory-Evans C, Emmett W, Waseem N, Raby J, Prescott D, Moore AT, Bhattacharya SS: Wolfram gene (WFS1) mutation causes autosomal dominant congenital nuclear cataract in humans. Eur J Hum Genet 2013, 21(12):1356-1360.

17. Numoto N, Kita A, Fujii N, Miki K: A P39R mutation at the N-terminal domain of human $\mathrm{aB}$-crystallin regulates its oligomeric state and chaperone-like activity. Biochem Biophys Res Commun 2012, 425(3):601-606 
18. Chen $\mathrm{Q}, \mathrm{Ma}$ J, Yan M, Mothobi ME, Liu Y, Zheng F: A novel mutation in CRYAB associated with autosomal dominant congenital nuclear cataract in a Chinese family. Mol Vis 2009, 15:1359-1365.

19. Sacconi S, Féasson L, Antoine JC, Pécheux C, Bernard R, Cobo AM, Casarin A, Salviati L, Desnuelle C, Urtizberea A: A novel CRYAB mutation resulting in multisystemic disease. Neuromuscul Disord 2012, 22(1):66-72.

20. Berry V, Francis P, Reddy MA, Collyer D, Vithana E, MacKay I, Dawson G, Carey AH, Moore A, Bhattacharya SS, Quinlan RA: Alpha-B Crystallin Gene (CRYAB) Mutation Causes Dominant Congenital Posterior Polar Cataract in Humans. Am J Hum Genet 2001, 69(5):1141-1145.

21. Devi RR, Yao W, Vijayalakshmi P, Sergeev YV, Sundaresan P, Hejtmancik JF: Crystallin gene mutations in Indian families with inherited pediatric cataract. Mol Vis 2008, 14:1157-1170.

22. Li H, Li C, Lu Q, Su T, Ke T, Li DW-C, Yuan M, Liu J, Ren X, Zhang Z, Zeng S, Wang QK, Liu M: Cataract mutation P20S of aB-crystallin impairs chaperone activity of aA-crystallin and induces apoptosis of human lens epithelial cells. Biochim Biophys Acta 2008, 1782(5):303-309.

23. Safieh $L A$, Khan $A O$, Alkuraya FS: Identification of a novel CRYAB mutation associated with autosomal recessive juvenile cataract in a Saudi family. Mor Vis 2009, 15:980-984

24. Sun W, Xiao X, Li S, Guo X, Zhang Q: Mutation analysis of 12 genes in Chinese families with congenital cataracts. Mol Vis 2011, 17:2197-2206.

25. Liu Y, Zhang X, Luo L, Wu M, Zeng R, Cheng G, Hu B, Liu B, Liang JJ, Shang F: A novel aB-crystallin mutation associated with autosomal dominant congenital lamellar cataract. Invest Ophthalmol Vis Sci 2006, 47(3):1069-1075.

26. Raju I, Abraham EC: Mutants of human aB-crystallin cause enhanced protein aggregation and apoptosis in mammalian cells: Influence of co-expression of HspB1. Biochem Biophys Res Commun 2013, 430(1):107-112.

doi:10.1186/1471-2415-14-108

Cite this article as: Xia et al:: A novel P20R mutation in the alpha-B crystallin gene causes autosomal dominant congenital posterior polar cataracts in a Chinese family. BMC Ophthalmology 2014 14:108.

\section{Submit your next manuscript to BioMed Central and take full advantage of:}

- Convenient online submission

- Thorough peer review

- No space constraints or color figure charges

- Immediate publication on acceptance

- Inclusion in PubMed, CAS, Scopus and Google Scholar

- Research which is freely available for redistribution 